\title{
Book Review: The Routledge International Handbook of Ethno- graphic Film and Video
}

By Phillip Vannini, Routledge. 2020. ISBN: 9780367185824 . \$250.00 (Print). Reviewed by Fernando Nobre Cavalcante, University of Campinas

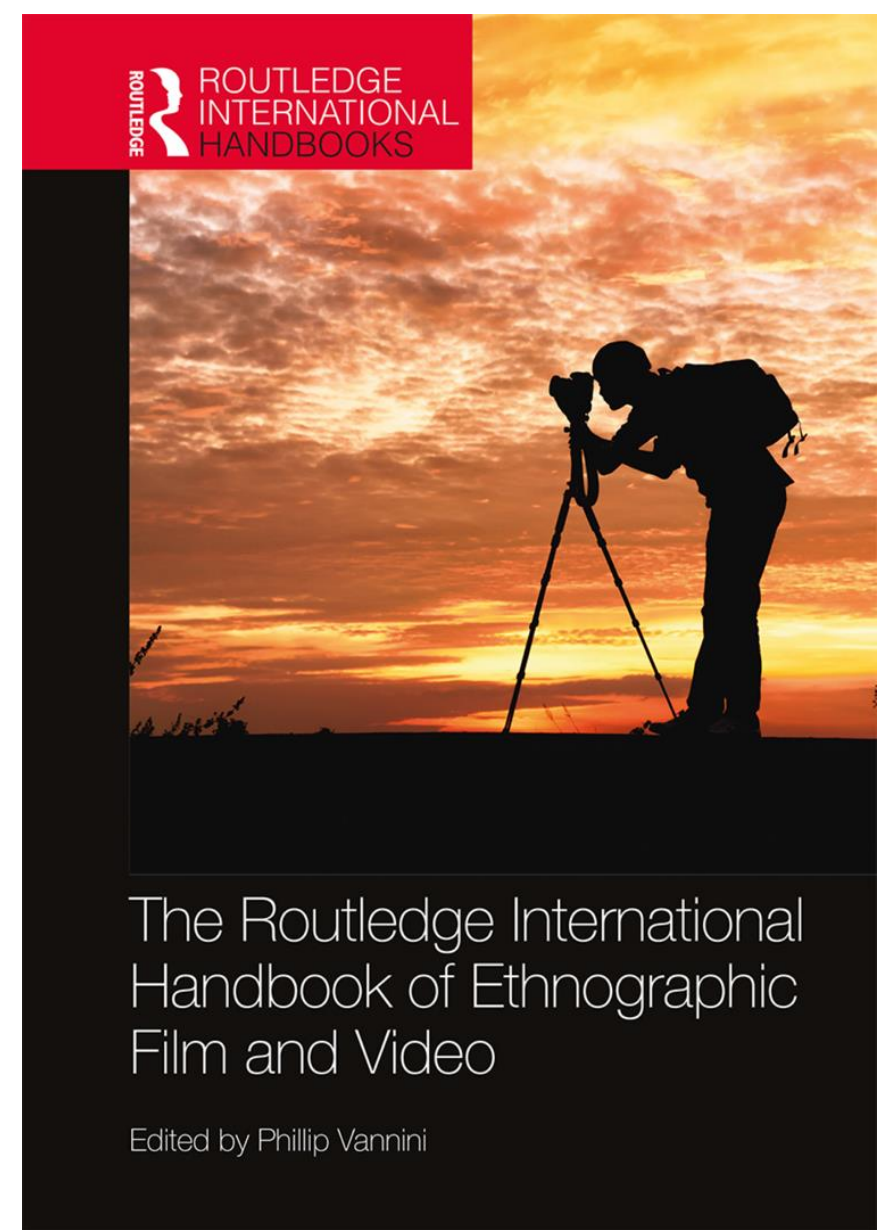

This handbook seeks to engage the ethnography scholar by presenting the readers to the technical image in motion, its processes, and the territories from which it emerges. For those working in user experience (UX research), it is an opportunity to consolidate a deeper understanding of media-centric ethnography. Rather than debating public policies, the work aspires to preserve the anthropological knowledge of native peoples by considering that the making of a book is similar to the image of woven networks and the reflection of the national educational policy. This handbook asserts that there is a new generation of researchers born from media and communication studies who believe in ethnography as the means of an interdisciplinary anthropology. Guidelines for a foundation in the field of media ethnography are considered in this compilation, conceiving theories and experiments on ways of mobilizing scientific knowledge stemming from ethnographic films and videos. The handbook suggests a visual ethnography through theorization and practice, and addresses the following topics: discourse, representation, territorial debate, social mobilizations, regional struggles, queer and feminist approaches, distribution and circulation of cultural products, and interactions centered on the media. Edited by the ethnographer and filmmaker Phillip Vannini and published by Routledge (Taylor Francis Group), the handbook is organized into 31 chapters that set the tone for a new field of anthropological research in the face of constructing a paradigm mediatized from reality. Vannini has also been a professor in the School of Communication and Culture at Royal Roads University in Victoria, Canada, since 2011; the work is his 16th book. His classic Doing Public Ethnography (2018) possibly influenced him in organizing the handbook by insisting on the methodological contribution of "how to do" public ethnography.

This handbook sensitizes us with a provocative introduction that takes the reader to the intended vital questioning: i) how to expand the anthropological spectrum in view of its technological complexity, and ii) how to attract new audiences to scientific discoveries. In addition to the quantitative-descriptive standard, typical of handbooks, 
which are closer to an ethno-dramatic narrative, it questions the definition and role of cinematographic ethnography. It approaches the technique of media professionals by convincing the reader that, in documentary daily lives, there are anthropological latencies, even without the honor of the disciplinary academic license of research in a specific area of knowledge. It dedicates some attention to attract non-academic readers, proposing that the narratives of the professional experiences combine with "academicism" due to the expertise of technical and field intimacies by stimulating the (re)construction of reality through technical images, from film festivals to video journals, interactive documentaries, and drone or $360^{\circ}$ videos.

The handbook totals 359 persuasive pages about using these and other video and film techniques for geography, sociology, education, history, cultural studies, gender studies, environmental studies, media studies, and anthropology. In general, the authors of each chapter captivate the reader by attributing an ethnographic film character as a tool in the collection of data, procedural in the investigative and strategic wandering, by the approximation/mobilization with/on the field. The chapters amplify the use of media, more specifically imagery framing (Youtube, Vimeo, Instagram, Skype, etc.), as a means of recording and collecting, as well as a transdisciplinary environment of experiences for the publication of ethnographic films. It presents technology as an ally accessible to qualitative studies in the field of Social and Human Sciences, leading it to a purely discursive/imagery mentality. The author strives in the first part of the book to theorize concepts of film ethnography and methodological processes by exploring the scene of film festivals that challenge ethnographic knowledge. P. Kerim Friedman makes ethnographic films to be understood as records, texts, sense impressions, or practical relations; analyzing film festivals in four dimensions: as dialog, subject, style, and methodological norms. Along with Jenny Chio, he sets the first part (six chapters) to consider film festivals in Asia as a catalyst for a theorization intended in the first proposal of the handbook. The role of the "other," philosophically speaking, of aesthetics, of representation and of multimodality of ethnographic films are also covered along different chapters. The second part (five chapters) of the handbook more closely covers the methodological tendencies in the areas of linguistics, ethnomethodology, psychology, and feminist studies and queer studies. Among so many renowned authors, Asta Cekaite provides relevant knowledge on the transdisciplinarity of ethnomethodology and its potential in the use of cinematographic ethnography for studies of face-to-face conversations.

Part 3 (five chapters) distinguishes the genres and styles of ethnographic films. More strictly speaking, the section focuses on experiences in the United States, New Zealand, Australia, and Europe (United Kingdom). Briefly, it can be seen that the films categories are alluded to for the sensoriality of the production, which are more visual, auditory, hybrid or interactive. Peter Biella, an anthropologist of the media, makes a historical apparatus of interactive features from 1978 to 2019, showing the implications of different types of technological immersion used by the anthropology of media. The use of videos in field investigation and the strategy to bring communities together is presented in Part 4 (4 chapters), whose topics range from latinx experiences in Pennsylvania to collaborative performance groups in São Paulo. The inclusion of Latin America in the debate's agenda is attributed to Jasper Chalcraft and Rose Satiko Gitirana Hikiji when they examined the ethical, aesthetic, and technical issues of decolonial post-production. In both sections, the reader will find clear traces of the importance of territoriality as a stylistic strategy and as access to the field. 
Part 5 (4 chapters) includes European experiences using new technologies, such as $360^{\circ}$ videos, wearable cameras, and drones. It points to the technological evolution in video as new anthropological horizons by revealing experiences in the United Kingdom, Holland and Germany. The sixth part (4 chapters) highlights the importance of regionalizing anthropological knowledge through film festivals, cultivation of media activism, and transdisciplinarity by bringing together media professionals and the academia. A debate on the distribution and circulation of ethnographic films is presented, encouraging the reader about planning for the circulation of visual investigation materials.

Phillip Vannini, Peter Biella, Alexandrine Boudreault-Fournier, Carlo Cubero, Lorenzo Ferrarini, Harjant Gill, Kathy Kasic, Molly Merriman, Mark Westmoreland, and Chris Wright conclude the last chapter of the handbook in a roundtable discussion. They pave the paths of versatile skills which media anthropologists use in dealing with creative, narrative, and investigative designs, techniques through editing and recording, and distribution to attract new audiences that build their worlds from technical images. They also discuss the challenges of location, remote work, new ways to attract public attention, and innovations of techniques to improve experiences with the ethnographic production media. Questions on how the intensified use of media result in scientific film production, and to whom they are intended, echo throughout the book. Even without citing or making references to the terms "media history", "mediatization" and "datafication", the handbook is a singular opportunity for those who want to thrive in the studies of figurative communications. It is especially useful for researchers who portray images scientifically, and for those wishing to expand their audience and the methodological approach of their ethnographic activities.

\section{References:}

Vannini, P. (2018) Doing Public Ethnography: How to Create and Disseminate Ethnographic and Qualitative Research to Wide Audiences. Routledge.

Vannini, P. (2020) The Routledge International Handbook of Ethnographic Film and Video. Routledge, Taylor \& Francis Group. 